\title{
Cancer Chemoprotective Effects of Cruciferous Vegetables
}

\author{
Jed W. Fahey and Katherine K. Stephenson \\ The Johns Hopkins University School of Medicine, Department of Pharmacology and Molecular Sciences, \\ Brassica Chemoprotection Laboratory, 725 N. Wolfe Street, Baltimore, MD 21205-2185
}

An extensive body of epidemiological evidence supports the contention that high fruit and vegetable consumption is associated with a reduction in the incidence of cancer at multiple sites. Block and her colleagues (1992) conclude that "major public health benefits could be achieved by substantially increasing the consumption of these foods" (Block et al., 1992; Steinmetz and Potter, 1996; Verhoeven et al., 1996). It is not yet clear how much of this risk reduction can be ascribed to the nutrient or non-nutrient components of these foods, and to what extent indirect effects (such as a parallel reduction in fat intake and increases in fiber, vitamin and carotenoid intake) may be responsible for this protection. These epidemiological studies further support the contention that as much as $75 \%$ to $80 \%$ of human cancers are related to "non-genetic" factors (Doll, 1992). Smoking and diet are commonly regarded as the most important of these factors. Most recent estimates are that diet is responsible for from $20 \%$ to $33 \%$ of all cancers that occur in economically developed countries (Willett and Trichopoulos, 1996) and the effect of diet has been the subject of a recent and extensive review (World Cancer Research Fund, 1997). The burden of cancer (estimated at 1.4 million new cases and $\approx 0.5$ million deaths in the United States in 1997 alone) could be reduced substantially by a combination of public health measures (avoiding certain risky habits or behaviors) or by administration of protective agents (a strategy termed chemoprotection, chemoprophylaxis, or chemoprevention).

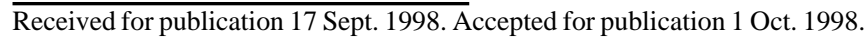
The assistance of James McFerson and Paul Kisley (U.S. Dept. of Agriculture, Geneva, N.Y.), John Bouwkamp (Dept. of Horticulture, Univ. of Maryland), and numerous members of the Maryland Organic Food and Farming Association (MOFFA) for growing and custom harvesting cruciferous plants in field and greenhouse plots is gratefully acknowledged. These studies were supported by grants from the Friends of the Brassica (philanthropic donors to the Brassica Chemoprotection Laboratory), the Rex Foundation, the American Institute for Cancer Research and the National Cancer Institute (PO1 CA44530). The cost of publishing this paper was defrayed in part by the payment of page charges. Under postal regulations, this paper therefore must be hereby marked advertisement solely to indicate this fact.

\section{INDUCTION OF DETOXICATION ENZYMES}

Since high fruit and vegetable consumption is associated with a striking reduction in malignancies at multiple organ sites, interest has grown steadily in recent years to develop diet-based chemoprotection strategies. One of the guiding principles in the development of dietary chemoprotective strategies has been the identification of chemical agents that induce Phase 2 detoxication enzymes in mammalian tissue (Kensler, 1997; Talalay, 1992). These enzymes (e.g., glutathione-Stransferase, quinone reductase, and epoxide hydrolase) inactivate reactive carcinogens by destroying their reactive centers or by conjugating them with endogenous ligands, thereby facilitating their elimination from the body (Fig. 1; Talalay, 1992). The causal relationship between Phase 2 enzyme induction and protection has been firmly established (Prochaska and Talalay, 1992). Recently, special attention has been accorded to edible plants that are rich in plant secondary metabolites (frequently termed "phytochemicals") responsible for

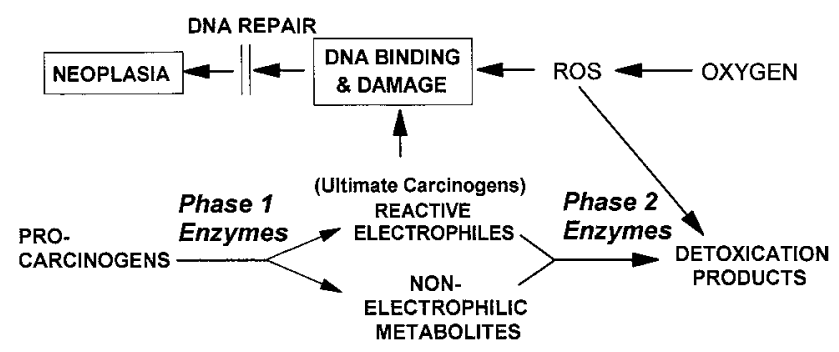

Fig. 1. Role of metabolism in chemical carcinogenesis. Susceptibility to carcinogen damage is controlled by balance between Phase 1 enzymes that activate and Phase 2 enzymes that detoxify carcinogens. (ROS = reactive oxygen species; Phase 1 enzymes are typified by cytochromes P-450; Phase 2 enzymes are typified by glutathione transferases, UDPglucuronosyltransferases and $\mathrm{NAD}(\mathrm{P}) \mathrm{H}$ :quinone reductase). 
induction of Phase 2 enzyme activity (Fahey et al., 1997; Jang et al., 1997; Kennelly et al., 1997; Prochaska et al., 1992; Zhang et al., 1992b). Viewed in the context of the epidemiological evidence cited above, and by a growing number of in vivo animal and clinical studies that are beyond the scope of this paper, the identification of Phase 2 enzyme elevation by specific phytochemicals strongly suggests the involvement of these compounds in cancer chemoprotection. Among crucifers [e.g., broccoli (Brassica oleracea L. var. italica Plenck), cabbage (B. oleracea var. capitata L.), cauliflower (B. oleracea var. botrytis L.)] this inducer activity is principally due to the highly reactive isothiocyanates $(\mathrm{R}-\mathrm{N}=\mathrm{C}=\mathrm{S})$ otherwise known as mustard oils (see Zhang and Talalay, 1994). The isothiocyanate sulforaphane, the most potent naturally occurring inducer, was isolated from broccoli in this laboratory based upon its very potent Phase 2 enzyme inducer activity in a bioassay (Zhang et al., 1992b), and its anticarcinogenic activity was demonstrated in a rat mammary tumor model (Zhang et al., 1994). Glucosinolates are very stable precursors of isothiocyanates, which are typically present in crucifers at vastly higher levels than are isothiocyanates. The relatively non-reactive glucosinolates are hydrolyzed to isothiocyanates by the coexisting, but physically segregated, enzyme myrosinase ( $\beta$-thioglucoside glucohydrolase; EC 3.2.3.1). This enzyme is released from plant cells upon wounding, chewing or other damage (Bones and Rossiter, 1996), including bruising or freeze-thawing, during cultivation, harvest, shipping, or handling (Rosa et al., 1997) and, probably, in animal digestive systems (Campbell et al., 1987; Deidrich and Kujowa, 1987; Nugon-Baudon et al., 1988). Subsequently, the glucose moiety is enzymatically cleaved from the molecule, the sulfate moiety is released and the molecule undergoes a rearrangement to form isothiocyanates and other breakdown products as depicted below.

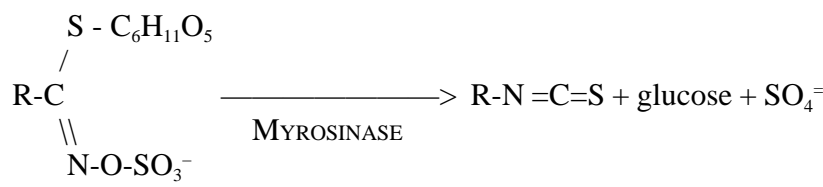

GLuCOSINOLATE

ISOTHIOCYANATE

Glucosinolates are very stable, water-soluble compounds that can occur at levels on the order of $1 \%(\mathrm{w} / \mathrm{w})$ in specific tissues of certain plant species (Rosa et al., 1997). They constitute $\approx 0.05 \%$ to $0.1 \%$ of the fresh weight of broccoli $\left(\approx 0.5-1.0 \mathrm{~g} \cdot \mathrm{kg}^{-1}\right)$. Their isothiocyanate congeners, however, are often highly reactive and/or volatile (Lüthy and Matile, 1984). Almost all of the inducer activity from crucifers is due to isothiocyanates, and the hydrolysis of glucosinolates by myrosinase is presumably a prerequisite for biological activity.

\section{ISOLATION AND IDENTIFICATION OF GLUCOSINOLATES}

Glucosinolates were first isolated in the middle of last century and much effort has been devoted to developing methods for their efficient isolation and identification (Betz and Fox, 1994). Existing methods for separation involve ion exchange, gas chromatography (GC), and high performance liquid chromatography (HPLC), mostly after chemical modification by enzymatic sulfate removal and/or silylation of sugar moieties. However, chromatographic standards of glucosinolates are difficult to obtain and biological activity of the molecule is compromised by the derivatization procedures required for GC and HPLC techniques utilized for their separation. We have therefore developed methods for the separation and identification of individual glucosinolates in plant extracts by: 1) paired ion chromatography in the presence of tetraoctyl- or tetradecyl-ammonium bromide (used in conjunction with myrosinase hydrolysis and isothiocyanate assay by cyclocondensation);2) a novel method for replacement of the counterion by $\mathrm{NH}_{4}^{+}$, which is essential for bioassay and mass spectroscopy; 3 ) improvements in mass spectroscopic analysis by combined fast atom bombardment and chemical ionization techniques; and 4) high resolution nuclear magnetic resonance (NMR) spectroscopy, which provides final confirmation of identity (Prestera et al., 1996). Such a combination of steps provides a powerful method for rapidly characterizing and quantifying glucosinolates.

For the quantification of isothiocyanates in plant extracts, a sensitive assay was developed that exploits the ability of isothiocyanates to react with 1,2-benzenedithiol to form a cyclic thiocarbonyl reaction product, 1,3-benzodithiole-2-thione $\left(\mathrm{A}_{\mathrm{m}}=23,000 \mathrm{M}^{-1} \cdot \mathrm{cm}^{-1}\right.$ at $\left.365 \mathrm{~nm}\right)$ (Zhang et al., 1992a). We can now measure as few as 10 pmol of isothiocyanates in complex biological fluids such as plant extracts by modification of this technique for HPLC (Zhang et al., 1996). There is excellent correlation $(\mathrm{R}=0.99)$ between total glucosinolate titer, as determined by measuring isothiocyanates produced by the action of exogenous purified myrosinase on extracted glucosinolates, and the levels of these glucosinolates measured directly by the paired ion chromatography techniques referred to above (Fig. 2).

\section{EFFECTS OF PLANT GROWTH ENVIRONMENT ON PHASE 2 ENZYME INDUCER ACTIVITY}

Numerous studies have highlighted the complex and interrelated effects of cultural practices and environmental conditions on the production of plant secondary products such as the glucosinolates (Clossais-Besnard and Larher, 1991; Ishii and Saijo, 1987; Josefsson and Appelqvist, 1968). We have examined four different aspects of these environmental effects (preliminary results described herein), in order to look for temporal and spatial relationships of glucosinolate levels, and have confirmed that, in cultivated broccoli, glucosinolate levels are environmentally sensitive and are difficult to predict. In the first of these studies, 25 different cruciferous vegetables, predominantly broccoli, daikon (Raphanus sativus L), and cabbage, were planted at 11 sites representing a diversity of growing conditions. Phase 2 inducer activity varied tremendously among species and test sites. Second, soil fertility had a significant effect (95\% confidence level) on Phase 2 enzyme induction by extracts of broccoli cultivars Green Comet and Excelsior when two levels of municipal compost were compared with conventional tillage. In a third trial, the levels of glucoraphanin (as a surrogate for Phase 2 enzyme inducer activity) and other glucosinolates in two prolific, lateral-shooting broccoli cultivars were examined in weekly floret harvests from the same plants over a period of $>2$ months (Fig. 3). There was no consistent pattern of variation in any of the glucosinolates [levels of total glucosinolates on a fresh-weight basis ranged from 2 to $4 \mu \mathrm{mol} \cdot \mathrm{g}^{-1}$ and from 2 to 8 $\mu \mathrm{mol} \cdot \mathrm{g}^{-1}$, respectively, for U.S. Dept. of Agriculture (USDA) accessions P.I. 28210 and P.I. 28830]. Whereas the total glucosinolate level remained relatively constant in the former cultivar, levels of glucoraphanin (GR) and glucobrassicin (GB) fluctuated dramatically

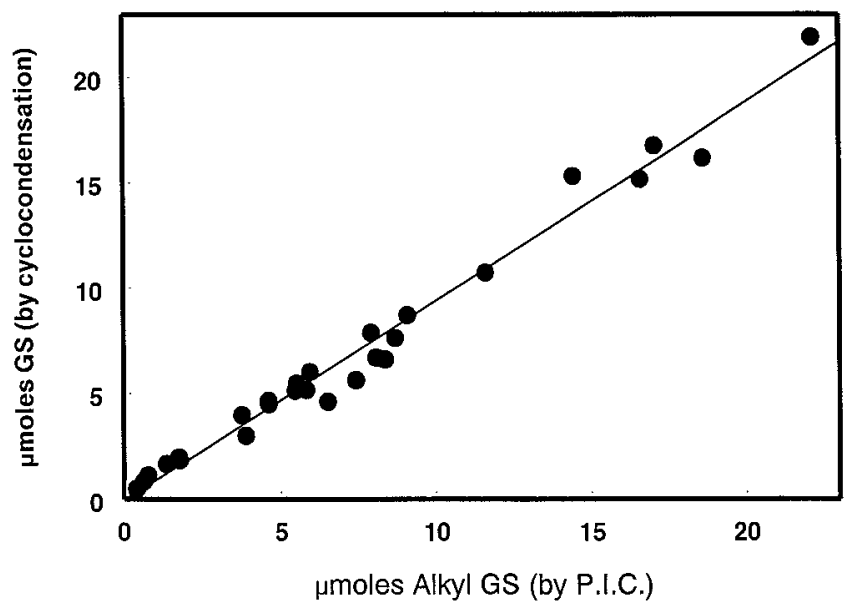

Fig. 2. Comparison of measurement by cyclocondensation of isothiocyanates produced by the action of exogenous, purified myrosinase from extracted glucosinolates of a group of 25 broccoli samples vs. direct measurement of total glucosinolate (GS) content on these extracts by paired ion HPLC. Note the excellent linear correlation $(\mathrm{R}=0.99)$ 
and were inversely correlated. In the latter cultivar there also were dramatic fluctuations, but GR levels were consistently higher than GB levels. A fourth trial assessed the effect of plant part on Phase 2 enzyme-inducing activity using broccoli cultivars Green Comet and Excelsior. Floret tissues had significantly higher (99\% confidence level) quantities of Phase 2 inducer activity than did stem or leaf tissues, but floret positions on the head did not affect inducer activity significantly (Fig. 4). Differences between cultivars were also significant at $P \leq 0.01$. These data confirm that the majority of the Phase 2 enzyme-inducing activity resides in immature (market-stage) florets, in which activity was 5-fold as great as in stem tissue.

\section{EFFECTS OF SOURCE, TREATMENT, AND STORAGE ON PHASE 2 ENZYME INDUCER ACTIVITY}

Commercially frozen broccoli was examined with the knowledge that myrosinase-induced glucosinolate degradation can be minimized by a rapid ( $3 \mathrm{~min}$ ) boiling treatment. Much of the broccoli frozen for supermarket distribution comes from mixed sources, and therefore even single 1-lb (454 g) bags of frozen broccoli florets could be derived from multiple cultivars, depending upon season and harvest location. All frozen broccoli is blanched (a quick steam treatment) prior to freezing in order to eliminate the enzymatic degradation of the product that would occur slowly even at $<0^{\circ} \mathrm{C}$. Commercial frozen broccoli preparations from five different national producers had glucosinolate profiles similar to that of fresh broccoli in both quality and quantity (1$2 \mu \mathrm{mol}$ total glucosinolates/g frozen tissue). On average, the indole glucosinolates glucobrassicin, neoglucobrassicin, and 4-hydroxyglucobrassicin accounted for roughly half of the glucosinolates; alkylthioalkyl glucosinolates $(\approx 88 \%$ GR) accounted for the other half. The known activity of sulforaphane (the isothiocyanate produced by breakdown of GR) always accounted for almost all of the Phase 2 inducing activity of myrosinase-treated broccoli extracts. In a typical survey, 31 fresh, raw heads of broccoli, each purchased from a different Baltimore area supermarket, had an average GR content of $0.38 \pm 0.21 \mu \mathrm{mol} \cdot \mathrm{g}^{-1}$ with a range of $\approx 0.00$ (below the limits of detection; <0.005) to 1.13 $\mu \mathrm{mol} \cdot \mathrm{g}^{-1}$ on a fresh-weight basis. When extracts of these heads were individually bioassayed for Phase 2 enzyme inducer capacity, the correlation between inducer potential and glucoraphanin levels was very high $(\mathrm{R}=0.94)$.

Fresh broccoli purchased at local supermarkets at different times (in order to minimize local supplier effects) had glucosinolate profiles similar to those of commercial frozen broccoli, and samples could not be differentiated based on visual inspection or odor (Fahey et al., 1997). Storage or handling, however, can reduce the quantity of glucosinolates present in fresh cruciferous vegetables (Howard et al., 1997). The inducer potency begins to decline when glucosinolates are converted to isothiocyanates as a result of the release of myrosinase during harvest, shipping, storage and handling, as well as during the natural aging process in vegetables stored, even under refrigeration, for too long a period of time. The highly reactive isothiocyanates (the active chemoprotective agents) are rapidly degraded or may volatilize. The vegetable therefore starts to lose its chemoprotective titer as soon as it is picked and the loss continues throughout the storage and handling process.

\section{QUALITATIVE EVALUATION OF GLUCOSINOLATES IN BROCCOLI}

The concept of "good" vs. "bad" glucosinolates is justified based on a careful reading of the scientific literature and thus merits attention for the following four reasons: 1) low cytotoxicity and high detoxifying enzyme induction activity of alkylthioalkyl glucosinolates; 2) weak induction of detoxication enzymes and substantial induction of Phase 1 enzymes by the indole glucosinolates; 3 ) formation of highly toxic compounds from the indole glucosinolates; and 4) production of goitrogenic compounds from the -hydroxyalkenyl glucosinolates. First, the common alkylthioalkyl glucosinolates (e.g., glucoraphanin, glucoiberin and glucoerucin) form isothiocyanates (sulforaphane, iberin and erucin, respectively) with low cytotoxicity and high Phase 2 enzyme-inducing activity. For example, sulforaphane is the most

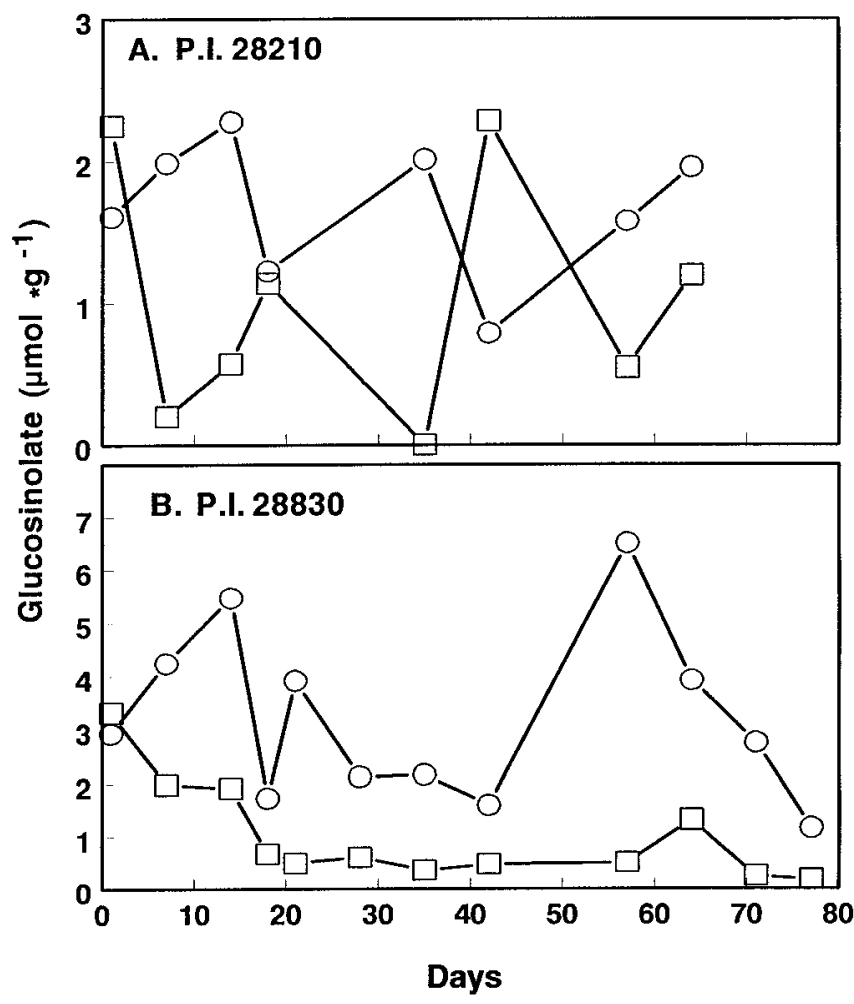

Fig. 3. Levels of glucoraphanin and glucobrassicin in two broccoli genotypes. Paired ion HPLC of extracts of florets harvested periodically over 2.5 months from the same two plants grown in Geneva, N.Y., in 1996. Genotypes: U.S. Dept. of Agriculture Plant Introduction (P.I.) accessions 28210 (A) and 28830 (B); (О) glucoraphanin; ( $\square$ ) glucobrassicin.

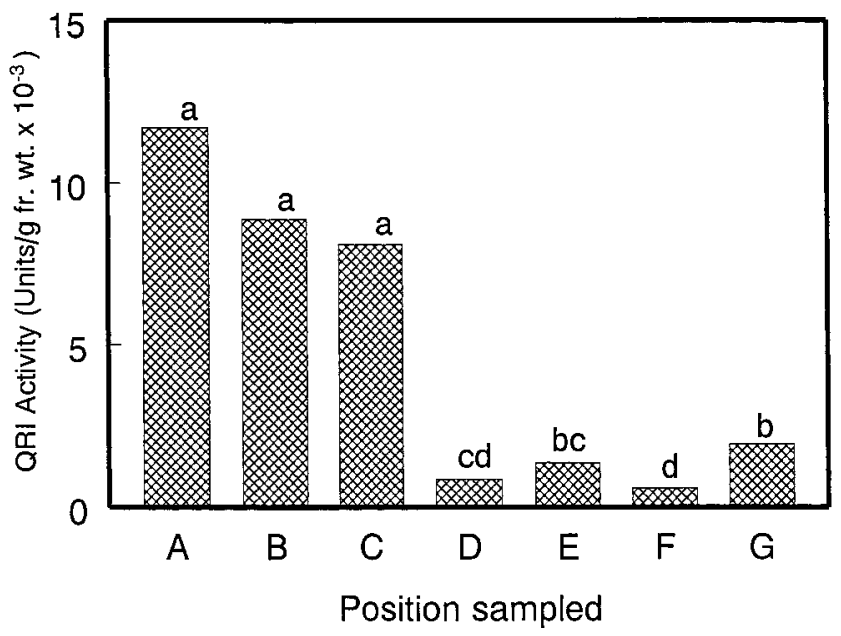

Fig. 4. Effect of sample position on quinone reductase inducer (QRI) activity in two broccoli cultivars (Green Comet and Excelsior) grown in Wye, Md., in 1994. Twenty market stage heads were harvested from each cultivar (harvest weights ranged from 314 to $664 \mathrm{~g}$ ), and tissue samples (1-6g) were immediately removed and frozen on dry ice prior to homogenization in 10 volumes of cold solvent, from each of the following locations: A, top center of head; B, middle of head; C, lower perimeter of head; D, top of stalk; E, middle of stalk; F, base of stalk; G, first leaf subtending the head. QRI assay was performed in 96-well microtiter plates with exogenous myrosinase as described in Fahey et al. (1997). Mean separation $(\mathrm{t}=1.98, \mathrm{LSD}=0.244)$ by Student's $t$ test at $P \leq 0.05 ; \mathrm{n}=20$ (10 from each cultivar) for all positions sampled. 
potent naturally occurring Phase 2 enzyme inducer identified (Zhang et al., 1992b) and has very low cytotoxicity (Barcelo et al., 1996). These compounds are monofunctional inducers in that they do not concomitantly induce Phase 1 enzymes that can activate xenobiotics, thus converting them into carcinogens (Prochaska and Talalay, 1988). Second, indole glucosinolates (e.g., glucobrassicin, neoglucobrassicin, 4-hydroxyglucobrassicin, 1-hydroxyglucobrassicin and 4methoxyglucobrassicin) do not form stable isothiocyanates, but form compounds such as indole-3-carbinol, indole-3-acetonitrile, and 3,3'diindolylmethane via unstable isothiocyanate intermediates (Ames et al., 1990; Bradfield and Bjeldanes, 1987; McDanell et al., 1988). We have found these compounds to be only weak inducers of Phase 2 detoxification enzymes. For example, the potency of indole-3-acetonitrile is $<0.5 \%$ of that of sulforaphane, the breakdown product of glucoraphanin. However, these compounds are bifunctional inducers so that they can participate in the formation of carcinogens by modulating the metabolic activation of procarcinogens. Thirdly, in the acid conditions encountered in the human stomach, indole-3-carbinol can spontaneously form condensation products that have toxicities similar to those of dioxin (TCDD), the potent carcinogenic contaminant of "Agent Orange" (Bjeldanes et al., 1991). Metabolic derivatives of indole glucosinolates can thus simultaneously both promote and prevent cancer. Fourthly, another class of glucosinolates, the hydroxyalkenyl glucosinolates (e.g., progoitrin and epiprogoitrin) are metabolically converted to goitrogenic oxazolidonethiones. Overconsumption of certain cruciferous vegetables, such as kale and cabbage, causes goiter in both experimental animals and humans and may be responsible for the development of endemic goiter in certain regions (Michajlovski et al., 1969). Although certain crucifers such as cabbage and the oilseed crops crambe (Crambe maritima L.) and rapeseed (Brassica napus L. and B. campestris L. = B. rapa L.) contain large quantities of the goitrogenic glucosinolates, broccoli contains insignificant quantities of these compounds (Rosa et al., 1997).

Considerable degradation of the indole glucosinolates occurs upon cooking (i.e., boiling or microwaving) (Betz and Fox, 1994; Slominski and Campbell, 1989). Our analysis of samples of five national brands of frozen broccoli and of five different broccoli cultivars organically grown in Maryland shows that the predominant glucosinolates are glucoraphanin (GR), glucobrassicin (GB) and neoglucobrassicin, with lesser quantities of 4-hydroxyglucobrassicin and glucoiberin. We obtained unequivocal identification of these compounds by chemical ionization mass spectroscopy of a representative commercially frozen broccoli sample (BirdsEye Broccoli Cuts, Lot\# 6x126-1; composed of cultivars Marathon, Patriot and/or Pilot). As previously discussed, the molar ratio of alkylthioalkyl glucosinolates like glucoraphanin (a "good" glucosinolate) to indole glucosinolates like glucobrassicin was $\approx 1: 1$ both in commercially frozen broccoli (mean $1.49 \pm 0.39$ ) and in 31 heads of randomly selected, fresh, raw broccoli obtained from Baltimore supermarkets (mean 1.25 \pm 0.79 ), which is consistent with the observations of others such as Goodrich et al. (1989). There was, however, a tremendous range in glucoraphanin content $(\approx 0.00-1.13$ $\mu \mathrm{mol} \cdot \mathrm{g}^{-1}$ in extracts of the raw heads), as well as in the ratio of GR to GB $(\approx 0.00$ to 3.64$)$ on a fresh-weight basis. Similar glucoraphanin contents with large plant-to-plant variation were observed in extracts of five broccoli cultivars grown organically in Maryland in 1994 (0.53, $0.90,1.03,1.53$ and $1.63 \mu \mathrm{mol} \cdot \mathrm{g}^{-1}$ of GR on a fresh weight basis for cultivars Emperor, Everest, Saga, DeCicco and Green Valiant, respectively). Preliminary results from a recently conducted survey of 27 broccoli cultivars grown in Geneva, N.Y., indicate a mean GR level on a fresh-weight basis of $0.76 \pm 0.41 \mu \mathrm{mol} \cdot \mathrm{g}^{-1}$ (range $\approx 0.00-1.98$ $\mu \mathrm{mol} \cdot \mathrm{g}^{-1}$ ) and a mean GR/GB ratio of $1.21 \pm 0.68$ (range $\approx 0.00-3.02$ ). In none of these samples were there any physical cues (e.g., appearance, smell, color) as to the glucoraphanin content (hence Phase 2 inducer potency) of these broccoli heads. Boiling for as little as $3 \mathrm{~min}$ destroys the activity of myrosinase and stabilizes the glucosinolate content of vegetables.

\section{CONCLUSIONS}

In conclusion, global efforts are being made to understand the complex effects of diet on cancer incidence (World Cancer Research
Fund, 1997). We have focused on minor dietary constituents that elevate the activity of cellular detoxication enzymes (Phase 2 enzymes) based on evidence indicating that induction of these enzymes blocks the formation of tumors in experimental animals. Sensitive analytical techniques have been developed for the quantitation of glucosinolates and of isothiocyanates, and these methods are being used to evaluate the anticancer potential of a range of cruciferous vegetables, as well as the environmental and genetic components of glucosinolate production. Although a reduction in total glucosinolate titer will occur upon short (3-5 min) boiling, the content of glucoraphanin will not be dramatically reduced. Since glucosinolates are water-soluble, cooking methods such as steaming, microwaving, stir-frying or rapid boiling with minimal water should be used in order to prevent excessive leaching and loss of these compounds. The utility of these plants in selectively elevating Phase 2 enzymes (but not Phase 1 enzymes) is a promising facet in the rational development of dietary strategies for reducing the risk of cancer.

\section{Literature Cited}

Ames, B.N., M. Profet, and L.S. Gold. 1990. Nature's chemicals and synthetic chemicals: Comparative toxicology. Proc. Natl. Acad. Sci. USA 87:77827786.

Barcelo, S., J.M. Gardiner, A. Gescher, and J.K. Chipman. 1996. CYP2E1mediated mechanism of anti-genotoxicity of the broccoli constituent sulforaphane. Carcinogenesis 17:277-282.

Betz, J.M. and W.D. Fox. 1994. High performance liquid chromatographic determination of glucosinolates in Brassica vegetables, p. 180-196. In: M.T. Huang, T. Osawa, C.-T. Ho, and R.T. Rosen (eds.). Food phytochemicals for cancer prevention. I. Fruits and vegetables. Amer. Chem. Soc., Washington, D.C.

Bjeldanes, L.F., J.-Y. Kim, K.R. Grose, J.C. Bartholomew, and C.A. Bradfield. 1991. Aromatic hydrocarbon responsiveness-receptor agonists generated from indole-3-carbinol in vitro and in vivo: Comparisons with 2,3,7,8tetrachlorodibenzo-p-dioxin. Proc. Natl. Acad. Sci. USA 88:9543-9547.

Block, G., B. Patterson, and A. Subar. 1992. Fruit, vegetables, and cancer prevention: A review of the epidemiological evidence. Nutr. Cancer 18:129.

Bones, A.M. and J.T. Rossiter. 1996. The myrosinase-glucosinolate system, its organisation and biochemistry. Physiol. Plant. 97:194-208.

Bradfield, C.A. and L.F. Bjeldanes. 1987. Structure-activity relationships of dietary indoles: A proposed mechanism of action as modifiers of xenobiotic metabolism. J. Toxicol. Environ. Health 21:311-323.

Campbell, L.D., B.A. Slominski, and N.E. Stanger. 1987. Influence of cecectomy and dietary antibiotics on the fate of ingested intact glucosinolates in poultry, p. 1704-1709. In: Proc. 7th Intl. Rapeseed Congr., Poznan, Poland.

Clossais-Besnard, N. and F. Larher. 1991. Physiological role of glucosinolates in Brassica napus. Concentration and distribution pattern of glucosinolates among plant organs during a complete life cycle. J. Sci. Food Agr. 31:549557.

Diedrich, M. and M. Kujawa. 1987. Degradation of progoitrin and its breakdown product VOT by microorganisms of intestine of rats in vitro, p. 1710 1716. In: Proc. 7th Intl. Rapeseed Congr., 1710-1716, Poznaín, Poland.

Doll, R. 1992. The lessons of life: Keynote address to the nutrition and cancer conference. Cancer Res. 52:2024s-2029s.

Fahey, J.W., Y. Zhang, and P. Talalay. 1997. Broccoli sprouts: An exceptionally rich source of inducers of enzymes that protect against chemical carcinogens. Proc. Natl. Acad. Sci. USA. 94:10367-10372.

Goodrich, R.M., J.L. Anderson, and G.S. Stoewsand. 1989. Glucosinolate changes in blanched broccoli and brussels sprouts. J. Food Proc. Preserv. $13: 275-280$.

Howard, L.A., E.H. Jeffery, M.A. Wallig, and B.P. Klein. 1997. Retention of phytochemicals in fresh and processed broccoli. J. Food Sci. 62:1098$1100,1104$.

Ishii, G. and R. Saijo. 1987. Effect of season, soil type, sulfate level, mulching, and plant density on isothiocyanate content in radish root juice (Raphanus sativus L.). J. Jpn. Soc. Hort. Sci. 56:313-320.

Jang, M., L. Cai, G.O. Udeani, K.V. Slowing, C.F. Thomas, C.W. Beecher, H.H. Fong, N.R. Farnsworth, A.D. Kinghorn, R.G. Mehta, R.C. Moon, and J.M. Pezzuto. 1997. Cancer chemopreventive activity of resveratrol, a natural product derived from grapes. Science 275:218-220.

Josefsson, E. and L.A. Appelqvist. 1968. Glucosinolates in seed of rape and turnip rape as affected by variety and environment. J. Sci. Food Agr. 19:564-570.

Kennelly, E.J., C. Gerhäuser, L.L. Song, J.G. Graham, C.W.W. Beecher, J.M. Pezzuto and A.D. Kinghorn. 1997. Induction of quinone reductase by withanolides isolated from Physalis philadelphica (tomatillos). J. Agr. 
Food Chem. 45:3771-3777.

Kensler, T.W. 1997. Chemoprevention by inducers of carcinogen detoxifying enzymes. Environ. Health Perspect. 105(Suppl.):964-970.

Lüthy, B. and P. Matile. 1984. The mustard oil bomb: Rectified analysis of the subcellular organisation of the myrosinase system. Biochem. Physiol. Pflanzen 179:5-12.

McDanell, R.E., A.E.M. McLean, A.B. Hanley, R.K. Heaney, and G.R. Fenwick. 1988. Chemical and biological properties of indole glucosinolates (glucobrassicins): A review. Food Chem. Toxicol. 26:59-70.

Michajlovskij, N., J. Sedlak, M. Jusic, and R. Buzina. 1969. Goitrogenic substances of kale and their possible relation to the endemic goitre on the Island of Krk (Yugoslavia). Endocrinol. Expt. 3: 65-72.

Nugon-Baudon, L., O. Szylit, and P. Raibaud. 1988. Production of toxic glucosinolate derivatives from rapeseed meal by intestinal microflora of rat and chicken. J. Sci. Food Agr. 43:299-308.

Prestera, T.P., J.W. Fahey, W.D. Holtzclaw, C. Abeygunawardana, J.L. Kachinski, and P. Talalay. 1996. Comprehensive chromatographic and spectroscopic methods for the separation and identification of intact glucosinolates. Anal. Biochem. 239:168-179.

Prochaska, H.J., A.B. Santamaria, and P. Talalay. 1992. Rapid detection of inducers of enzymes that protect against carcinogens. Proc. Natl. Acad. Sci. USA 89:2394-2398.

Prochaska, H.J. and P. Talalay. 1988. Regulatory mechanisms of monofunctional and bifunctional anticarcinogenic enzyme inducers in murine liver. Cancer Res. 48:4776-4782.

Prochaska, H.J. and P. Talalay. 1992. Phenolic antioxidants as inducers of anticarcinogenic enzymes, p. 150-159. In: M.-T. Huang, C.-T. Ho, and C.Y. Lee (eds.). Phenolic compounds in food and their effects on health II. Symp. Ser. 507, Amer. Chem. Soc., Washington, D.C.

Rosa, E.A.S., R.K. Heaney, G.R. Fenwick, and C.A.M. Portas. 1997. Glucosinolates in crop plants. Hort. Rev. 19:99-215

Slominski, B. and L.D. Campbell. 1989. Formation of indole glucosinolate breakdown products on autolyzed, steamed and cooked Brassica vegetables. J. Agr. Food Chem. 37:1297-1302.

Steinmetz, K.A. and J.D. Potter. 1996. Vegetables, fruit and cancer prevention: A review. J. Amer. Diet. Assoc. 96:1027-1039.

Talalay, P. 1992. The role of enzyme induction in protection against carcinogenesis, p. 469-478. In: L. Wattenberg, M. Lipkin, G.W. Boone, and G.J. Kelloff (eds.). Cancer chemoprevention. CRC Press, Boca Raton, Fla.

Verhoeven, D.T.H., R.A. Goldbohm, G. vanPoppel, H. Verhagen, and P.A. van den Brandt. 1996. Epidemiological studies on Brassica vegetables and cancer risk. Cancer Epidemiol. Biomarkers Prevent. 5:733-748.

Willett, W.C. and D. Trichopoulos. 1996. Nutrition and cancer: A summary of the evidence. Cancer Causes Control 7:178-180.

World Cancer Research Fund/American Institute for Cancer Research. 1997. Food, nutrition and the prevention of cancer: A global perspective. Amer. Inst. for Cancer Res., Washington, D.C.

Zhang, Y., C.-G. Cho, G.H. Posner, and P. Talalay. 1992a. Spectroscopic quantitation of organic isothiocyanates by cyclocondensation with vicinal dithiols. Anal. Biochem. 205:100-107.

Zhang, Y., T.W. Kensler, C.-G. Cho, G.H. Posner, and P. Talalay. 1994. Anticarcinogenic activities of sulforaphane and structurally related synthetic norbornyl isothiocyanates. Proc. Natl. Acad. Sci. USA 91:21472150 .

Zhang, Y. and P. Talalay. 1994. Anticarcinogenic activities of organic isothiocyanates: Chemistry and mechanisms. Cancer Res. 54 (Suppl.): 1976s-1981s.

Zhang, Y., P. Talalay, C.-G. Cho, and G.H. Posner. 1992b. A major inducer of anticarcinogenic protective enzymes from broccoli: Isolation and elucidation of structure. Proc. Natl. Acad. Sci. USA. 89:2399-2403.

Zhang, Y., K.L. Wade, T. Prestera, and P. Talalay. 1996. Quantitative determination of isothiocyanates, dithiocarbamates, carbon disulfide, and related thiocarbonyl compounds by cyclocondensation with 1,2-benzenedithiol. Anal. Biochem. 239:160-167. 